\title{
ADC E LSF: UM SUPORTE PARA A DESCONSTRUÇÃO DE REPRESENTAÇÕES EXCLUDENTES
}

\author{
(ADC and LSF: a support for deconstruction \\ of excludable representations)
}

Elaine Caldeira

\begin{abstract}
This study aimed to understand the discursive construction of xerente identities in texts built in a multicultural school by non-indians students. Based upon the epistemological perspective of Critical Discourse Analysis (CDA) (Chouliaraki \& Fairclough, 1999; Fairclough, 2001; 2003) and Systemic Functional Linguistics (SFL) (Halliday, 1991, 2004), this study aims analyze the role of the interpersonal speech-function of language taking as a tool for textual analysis of the categories of evaluation. The attributes and values intended for xerentes to reveal, in large part, the construction of a legitimating identity which obscures, deny, erase the differences. The analyzed texts reveal the presence of a hegemonic discourse which seeks to ensure that there is no difference between the representations, that "different representations can be legitimate particular ways of action and be inculcated in ways of identification" (Fairclough, 2003).

Keywords: discourse, evaluation, excludable representations; difference; identity.
\end{abstract}

\section{RESUMO}

Este trabalho buscou compreender a construção discursiva de identidades xerentes em textos construídos em um espaço escolar multicultural por estudantes não índios. Com base nos pressupostos teórico-metodológicos da Análise de Discurso Crítica (ADC) (Chouliaraki \& Fairclough, 1999; Fairclough, 2001; 2003) e da Lingüística Sistêmica Funcional (LSF) (Halliday, 1994; 2004), este trabalho tem como objetivo analisar o papel

1. Docente do Instituto Federal de Educação, Ciência e Tecnologia de Brasília - IFB. Mestre em Linguística - Análise do Discurso, UnB. 
da metafunção interpessoal tomando como instrumento de análise textual a categoria de avaliação. Os atributos e valores destinados aos xerentes revelam, em grande parte, a construção de uma identidade legitimadora que ofusca, nega, apaga as diferenças. Os textos analisados revelam, assim, a presença de uma voz hegemônica que visa assegurar que não haja diferença entre as representações, visto que "diferentes representações podem legitimar maneiras particulares de ação e ser inculcadas em modos de identificação" (Fairclough, 2003).

Palavras-chave: discurso; avaliação, representações excludentes; diferença; identidade.

\section{Introduçãoº}

A modernidade tardia ${ }^{3}$ refere-se a estilo, costume de vida ou organização social (Giddens, 1991: 11). Nessa nova conjuntura, as identidades são (des)construídas a partir de uma dinâmica diferente que, levando em conta aspectos mais amplos da vida social, fragmenta paisagens culturais de classe, gênero, etnia, sexualidade, raça e nacionalidade, que no passado nos tinham fornecido sólidas localizações como indivíduos sociais (Hall, 2009). Portanto, as identidades são vistas agora como "móveis", "fragmentadas", "contraditórias" multiplamente construídas por discursos, práticas e posições que podem se cruzar ou ser antagônicos (Giddens, 2002; Bauman, 2005; Hall, 2003, Bhabha, 1998; Silva, 2008).

Segundo Giddens, os modos de vida produzidos pela modernidade nos afastam de todos os tipos tradicionais da ordem social de uma maneira sem precedentes, visto que as transformações

2. Este trabalho é um recorte da pesquisa de mestrado "A constituição discursiva de identidades xerentes em um espaço escolar multicultural” realizada no Programa de Pós-Graduação em Linguística-PPGL/UnB.

3. O termo "modernidade tardia" está ligado a uma série de transformações que ocorreram no decorrer do século XX e provocaram alterações em vários níveis da vida humana. Segundo Giddens (2002: 221), esse fenômeno compreende "a presente fase de desenvolvimento das instituições modernas marcada pela radicalização e globalização dos traços básicos da modernidade". 
produzidas pela modernidade seriam mais profundas tanto em seu aspecto vertical quanto do ponto de vista horizontal (Giddens, 1991:14). A complexidade da vida moderna exige que assumamos diferentes identidades, identidades que podem estar em conflito (Woodward, 2008: 30). Um dos efeitos cruciais desse período, portanto, é o processo de desencaixe ${ }^{4}$, produzindo, para muitos, diferença, exclusão e marginalização. Assim, na modernidade tardia emerge a necessidade pela busca de "um novo sentido de identidade", pela desconstrução de determinadas representações, como um processo de "encontrar-se a si mesmo", pois a identidade passa a ser percebida como algo inacabado (Hall, 2000).

Com relação às identidades e suas transformações a partir dessa nova realidade, Castells (1999) diz, no que se refere aos atores sociais, que a identidade é um processo de construção de significado com base em um atributo cultural, ou ainda um conjunto de atributos culturais inter-relacionados, o(s) qual(is) prevalece (m) sobre as outras fontes de significado. Para um determinado indivíduo ou ainda um ator coletivo, pode haver identidades múltiplas. No entanto, essa pluralidade é fonte de tensão e contradição tanto na auto-representação quanto na ação social (Castells, 1999: 22).

Nesse direcionamento, Fairclough (2003) aponta que o discurso é "ferramenta" na construção e sustentação de determinadas representações sociais por grupos dominantes, visto que figura como elemento essencial para a sustentação e manutenção de relações hegemônicas ${ }^{5}$ em um dado contexto histórico. E por isso, analistas de discurso devem assumir um posicionamento crítico em relação

4. Um dos efeitos cruciais da modernidade tardia é o processo de desencaixe, conceituado como o 'deslocamento' das relações sociais de contextos locais de interação e sua reestruturação através de extensões indefinidas de tempo-espaço (Giddens, 1991: 29).

5. Hegemonia, no pensamento gramsciano, é concebida enquanto direção e domínio, isto é, como conquista, através da persuasão e do consenso, não atuando apenas no âmbito econômico e político da sociedade, mas também sobre o modo de pensar, sobre as orientações ideológicas e inclusive sobre o modo de conhecer. A hegemonia é a capacidade de unificar através da ideologia e de conservar unido um bloco social, não se restringindo ao aspecto político, mas compreendendo um fato cultural, moral, de concepção do mundo (Gramsci, 1995). 
aos problemas sociais com "facetas discursivas", visando desvelar, por meio da análise linguística, discursos que servem de base para manutenção de relações assimétricas de poder, isto é, para a prática discursiva abusiva de poder que gera desigualdade social.

Assim, com base nos pressupostos teórico-metodológicos da Análise de Discurso Crítica (ADC) (Chouliaraki \& Fairclough, 1999; Fairclough, 2001,; 2003), este trabalho tem como objetivo analisar o papel da metafunção interpessoal da linguagem (Halliday, 1994; 2001; 2004), proposta por Fairclough (2003) enquanto significado identificacional, na constituição discursiva da identidade dos índios xerentes em textos construídos em um espaço escolar multicultural, tomando como instrumento de análise textual a categoria de avaliação.

\section{Contextualização teórica}

Nas práticas sociais, o discurso se apresenta como ação, representação e identificação que, de acordo com Fairclough (2003), correspondem aos três significados do discurso: gêneros, discursos e estilos. Assim, o discurso figura primeiramente como parte da ação, pois uma das maneiras de agir e interagir é por meio da fala ou da escrita, o que nos possibilita distinguir diferentes gêneros como diferentes maneiras de (inter)agir discursivamente. Em segundo lugar, o discurso figura nas representações que sempre são partes de práticas sociais - representações do mundo material, de outras práticas sociais, representações próprias reflexivas da prática em questão. A representação ${ }^{6}$ é claramente substância discursiva, e podemos

6. De acordo com Hall (1997:25), construímos o significado das coisas "utilizando sistemas de representação - conceitos e signos". Para ele, a representação tem a ver com cultura e essa tem a ver com "significados partilhados". Assim, considera que a linguagem tem papel central para o significado e a cultura, pois tem sido considerada como o repositório chave dos valores e significados culturais, um dos meios privilegiados através dos quais é produzido e circula o significado. 
distinguir diferentes discursos, que podem representar a mesma área do mundo de diferentes perspectivas ou posições. Em terceiro lugar, discurso figura conjuntamente com expressões corporais ao constituir modos particulares de ser, identidades sociais ou pessoais particulares. Esse último significado é o que mais interessa a este trabalho.

Assim, partindo de uma visão multifuncional da linguagem e trazendo no centro de sua concepção uma postura emancipatória, que se empenha para tentar produzir transformações sociais por meio da análise crítica de discursos (Rajagopalan, 2003; Wodak, 2001), Chouliaraki e Fairclough (1999) e Fairclough (2001; 2003) enfatizam que cada vez mais o diálogo entre as teorias sociais e linguísticas, especialmente entre a Análise de Discurso Crítica (ADC) e a Linguística Sistêmica Funcional (LSF), devem se afinar, uma vez que essa visão multifuncional da linguagem torna possível investigar como escolhas léxico-gramaticais constituem representações, relações sociais e identidades sociais nos textos (Chouliaraki, 2000). Nesse sentido, Fairclough (2003) propõe uma recontextualização da perspectiva multifuncional da linguagem em LSF. As três metafunções apresentadas por Halliday (2004) (interpessoal - ideacional - textual) são renomeadas por Fairclough (2003) para significados do discurso.

Para Halliday (1994) essas três metafunções atuam simultaneamente em textos, pois, ao nos comunicarmos, utilizamos a linguagem realizando três tipos de significados simultâneos: um ligado ao relacionamento entre as pessoas (metafunção interpessoal), outro responsável pela representação do mundo (metafunção experiencial) e outro que dá à sentença seu status de mensagem (metafunção textual). Isso significa que "todo enunciado é multifuncional em sua totalidade" e "serve simultaneamente a diversas funções" (Resende \& Ramalho, 2006: 58).

Dessa forma, para Fairclough (2003) a representação corresponde à função ideacional de Halliday; a ação se aproxima de sua função interpessoal; e a identificação está na função interpessoal. Apesar de não chegar a ser uma novidade, segundo Resende (2009), já que Halliday falava em três linhas de significado, a diferença entre as propostas de Halliday e Fairclough no que se refere à multifuncionalidade linguística é significativa em termos do conteúdo 
de alguns desses significados, pois a proposta de Fairclough (2003) ampliou o diálogo entre a LSF e a ADC ao propor os conceitos de gênero discursos e estilos como associados aos significados acional, representacional e identificacional, respectivamente.

Segundo Fairclough (2003), podemos ver ação, representação e identificação simultaneamente em textos, e, por isso, focalizar a análise de textos na interação de ação, representação e identificação traz uma perspectiva social para análise de textos. Ele defende que há uma correspondência entre ação e gêneros, representação e discursos, identificação e estilos. Gêneros, discursos e estilos são, na ordem, meios relativamente estáveis e duráveis de agir, representar e identificar. São tidos como elementos de ordens de discurso no nível da prática social.

Fairclough (2003) aponta que quando analisamos textos específicos como parte de eventos específicos, estamos realizando duas tarefas interconexas: (a) olhando-as em termos dos três aspectos do significado: ação, representação e identificação e como são realizados nos diferentes traços de textos (vocabulário, gramática etc); (b) estabelecendo a ligação entre o evento social concreto e a prática social mais abstrata ao perguntar que gêneros, discursos e estilos estão ali delineados, e como os diferentes gêneros, discursos e estilos se articulam no texto.

Nessa perspectiva, a cada um desses modos de interação entre discurso e prática social ${ }^{7}$ corresponde um tipo de significado. Segundo Resende e Ramalho (2006: 60), "o significado acional focaliza o texto como modo de (inter) ação em eventos sociais, aproxima-se da função relacional", visto que "a ação legitima/questiona relações sociais"; "o significado representacional enfatiza a representação de aspectos do mundo - físico, mental, social - em textos, aproximando-se da função ideacional"; e, por sua vez, "o significado identificacional refere-se à construção e à negociação de identidades no discurso, relacionandose à função identitária”.

7. Para Fairclough (2000), a análise de práticas sociais constitui um foco "teoricamente coerente e metodologicamente efetivo" porque permite conectar a análise das estruturas sociais à análise da (inter)ação (Fairclough , 2000 apud Resende, 2009). 
Portanto, Fairclough (2003) apresenta esses significados como dialeticamente relacionados, já que considera que representações particulares (discursos) podem desempenhar de modo particular ações e relações (gêneros), e apontar modos de identificação (estilos). E é nesse sentido que, segundo Chouliaraki e Fairclough (1999), a ADC baseia-se na Linguística Sistêmica Funcional, visto que esta aborda a linguagem como um sistema aberto e funcional ${ }^{8}$, atentando para uma visão dialética que percebe os textos não só estruturados no sistema, mas também potencialmente inovadores do sistema. A linguagem é vista como um sistema aberto a mudanças socialmente orientadas, o que lhe provê capacidade teoricamente ilimitada de construir significados (Resende \& Ramalho, 2006).

\section{Significado identificacional: sistema de avaliação}

O significado identificacional está relacionado ao conceito de estilo. De acordo com Fairclough (2003: 156), estilos constituem o aspecto discursivo de identidades relacionando-se à identificação ${ }^{9}$ de atores sociais em textos. Segundo Chouliaraki e Fairclough (1999), podemos definir estilo como o "tipo de linguagem usado por uma categoria particular de pessoas e relacionado com a sua identidade", que expressa, de alguma forma, como pessoas se identificam e como identificam outras pessoas, por isso estilos relacionam-se com identificação.

Fairclough (2003) defende que as análises textuais que visam trabalhar com as formas de identificação devem se preocupar com traços linguísticos que permitem localizar determinados estilos. Ele aponta uma série de manifestações linguísticas, como por exemplo,

8. É funcional no sentido de que tem como função mostrar como a língua é usada. Uma gramática funcional é essencialmente uma gramática 'natural' no sentido de que tudo nela pode ser explicado, essencialmente, por referência ao uso da língua (Halliday, 1994).

9. A identificação deve ser vista como um processo dialético em que discursos podem ser inculcados em identidades (Fairclough, 2003: 156). 
advérbios de intensidade e vocabulário que, devido às escolhas variáveis que as pessoas fazem, carregam mensagens sobre identidades sociais particulares. Dentre as características relacionadas ao significado identificacional, destacamos neste estudo a avaliação ${ }^{10}$. Essa categoria contribui para compreendermos como as pessoas se avaliam e como avaliam as outras pessoas, ou seja, como (des)constroem discursivamente identidades sociais.

A avaliação inclui afirmações avaliativas (juízos de valor), afirmações com verbos de processo mental afetivo (odiar, gostar) e presunções valorativas (afirmações acerca do que é considerado desejável ou indesejável, bom ou ruim) (Fairclough, 2003 apud Resende \& Ramalho, 2006: 79). De acordo com Fairclough (2003: 172), o elemento avaliativo de uma afirmação pode ser um atributo, um verbo, um advérbio, que estão sujeitos a uma escala de intensidade. $\mathrm{Na}$ avaliação com verbo de processo mental afetivo podemos ter uma gradação entre a baixa e a alta afinidade e no caso das presunções valorativas, a avaliação não é engatilhada por marcadores relativamente transparentes de avaliação, em que os valores estão mais profundamente inseridos nos textos (Fairclough, 2003 apud Resende \& Ramalho, 2011:160-161).

Como o elemento avaliativo de uma afirmação, negativa ou positiva, pode ser um atributo, um verbo (processos mentais, processos relacionais etc), um advérbio, a análise do sistema de transitividade em muito pode colaborar na identificação e compreensão das ocorrências desses elementos avaliativos. O sistema da transitividade constitui-se "como o recurso léxico-gramatical geral para representar ações e atividades, construídas na gramática como configurações de processos ${ }^{11}$, dos participantes neles envolvidos e das circunstâncias que os enquadram e constrangem, constituindo-se assim, como o

10. A categoria avaliação, conforme utilizada nesta análise, foi sugerida por Fairclough (2003).

11. Os processos (representações linguísticas de atividades, ações e estados) têm, cada um, as suas características particulares e correspondem a seis possibilidades de realização, seis escolhas, assim designadas: processos materiais, processos mentais, processos relacionais, processos verbais, processos comportamentais e processos existenciais (Gouveia, 2009). 
recurso linguístico que dá conta de quem fez o quê a quem em que circunstâncias" (Gouveia, 2009: 30).

Os processos mentais são processos de sentir, pensar, ver, isto é, são processos que refletem atividades não no mundo exterior, mas no mundo interior, da mente (Thompson, 2004: 82). Os processos mentais podem ser de percepção (ver, ouvir, etc.), de cognição (compreender, conhecer, etc.) e de afeição (gostar, recear, amar, etc), tendo sempre um participante "consciente" que experiência, percepciona, conhece e sente (experienciador), e também um segundo participante, aquilo que é percepcionado, experimentado, conhecido, sentido (fenômeno) (Halliday, 2004: 208-210). Já os processos relacionais, processos de ser, ter e pertencer, possuem uma função classificatória, relacionando duas entidades no discurso (Halliday,1994: 119). Nos processos relacionais, a noção de ser/estar envolve duas partes ${ }^{12}$, isto é, de algo que se diz que é outra coisa qualquer, assim se relacionando duas entidades separadas.

\section{Geração e análise de dados}

Para compreender a realidade social representada nos textos adoto um método qualitativo de análise, pois de acordo com Bauer e Gaskell (2003) a pesquisa qualitativa é mais apropriada para interpretar realidades sociais. Flick (2004) também compartilha dessa visão, visto que a abordagem qualitativa considera a subjetividade do pesquisador e dos sujeitos pesquisados. O corpus deste trabalho é constituído por textos ${ }^{13}$ produzidos por alunos(as) não índios(as) sobre índios(as). A

12. Os participantes dos processos relacionais, que podem ser distinguidos em processos relacionais atributivos (intensivo, circunstancial e possessivo) e processos relacionais identificativos (intensivo, circunstancial e possessivo), são o portador e o atributo, que estabelecem entre si uma relação atributiva, e o identificado e o identificador, que estabelecem entre si uma relação de identificação (Halliday, 1994: 120 apud Gouveia, 2009).

13. É importante ressaltar que "textos" são assumidos, na ADC, como amostras de práticas sociais mais amplas, que se situam num nível intermediário entre o que tende a ser mais fixo (estruturas) e o que tende a ser mais flexível e momentâneo 
coleta de dados foi realizada em uma Escola de Ensino Médio, Colégio Estadual Frei Antônio, localizado na área urbana no município de Tocantínia, Estado do Tocantins. Foram realizadas visitas à Escola, e foi solicitado aos alunos(as) uma produção textual com a temática "Ser índio". Dentre esses, foram selecionados 22 (vinte e dois) textos de alunos(as) não índios(as) sobre alunos(as) índios(as) da etnia xerente.

Para realizar o levantamento dos enunciados, no que se refere à avaliação, levamos em consideração as afirmações que expressam desejos, vontades - o que é bom/mau, o que desejável/indesejável etc. As afirmações avaliativas, destaca Fairclough (2003: 173), são mais obviamente realizadas por processos relacionais que representam as categorias de atribuição e identificação. Com a finalidade de melhor identificar esses processos, realizamos a análise do sistema de transitividade no corpus selecionado.

Nos 22 textos selecionados para análise, foram encontrados 120 enunciados em que ocorre avaliação. A maioria dessas afirmações avaliativas foram realizadas por processos relacionais. Vejamos alguns exemplos nas análises abaixo:

(1)

\begin{tabular}{|c|c|c|}
\hline Ser índio & é & $\begin{array}{c}\text { ser igual a qualquer } \\
\text { pessoa. }\end{array}$ \\
\hline $\begin{array}{c}\text { Participante: } \\
\text { Portador }\end{array}$ & $\begin{array}{c}\text { Processo: Relacional atribu- } \\
\text { tivo intensivo }\end{array}$ & Participante: Atributo \\
\hline
\end{tabular}

(2)

\begin{tabular}{|c|c|c|}
\hline $\begin{array}{c}\text { A nação } \\
\text { indígena }\end{array}$ & é & uma cultura popular \\
\hline $\begin{array}{c}\text { Participante: } \\
\text { Portador }\end{array}$ & $\begin{array}{c}\text { Processo: Relacional atribu- } \\
\text { tivo intensivo }\end{array}$ & Participante: Atributo \\
\hline
\end{tabular}

(3)

(eventos). 


\begin{tabular}{|c|c|c|c|}
\hline Hoje & o índio & é & $\begin{array}{c}\text { igual a um } \\
\text { cristão }\end{array}$ \\
\hline \multirow{2}{*}{ Circunstância } & Participante: & Pelacional atributivo & Participante: \\
& Portador & intensivo & Atributo \\
\hline
\end{tabular}

\begin{tabular}{|l|c|l|c|}
\hline (eles) & vivem & socialmente & igual a nós \\
\hline $\begin{array}{c}\text { Participante: } \\
\text { Comportante }\end{array}$ & $\begin{array}{c}\text { Processo: Compor- } \\
\text { tamental }\end{array}$ & Circunstância & $\begin{array}{c}\text { Participante: } \\
\text { Comportamento }\end{array}$ \\
\hline
\end{tabular}

\begin{tabular}{|c|c|c|}
\hline O índio & tem & tudo de bom \\
\hline Participante: Portador & $\begin{array}{l}\text { Processo: Relacional } \\
\text { atributivo possessivo }\end{array}$ & Participante: Atributo \\
\hline
\end{tabular}

\begin{tabular}{|c|c|c|c|c|c|c|}
\hline o governo & dá & de tudo & para que & eles & procigam & a nação \\
\hline & & & & & & \\
Partici- & Processo & Partici- & Conector & Partici- & Processo: & Partici- \\
pante: & Material & pante: & & pante: & Material & pante: \\
Ator & & Meta & & Recebe- & & Meta \\
& & & & dor & & \\
\hline
\end{tabular}

(4)

\begin{tabular}{|c|c|c|c|c|}
\hline $\begin{array}{c}\text { Afinal das } \\
\text { contas }\end{array}$ & eles & são & como nós & (eles) \\
\hline Circunstância & $\begin{array}{c}\text { Participante: } \\
\text { Portador }\end{array}$ & $\begin{array}{l}\text { Processo: } \\
\text { Relacional } \\
\text { atributivo } \\
\text { intensivo }\end{array}$ & $\begin{array}{c}\text { Participante: } \\
\text { Atributo }\end{array}$ & $\begin{array}{l}\text { Participante: } \\
\text { Experienciador }\end{array}$ \\
\hline
\end{tabular}

\begin{tabular}{|c|c|c|c|}
\hline só & pensa & diferente & como todos os seres \\
\hline Circunstância & Processo: Mental & Participante: & Circunstância \\
& de cognição & Fenômeno & \\
\hline
\end{tabular}


(5)

\begin{tabular}{|c|c|c|c|c|c|c|}
\hline $\begin{array}{c}\text { Seu modo } \\
\text { de viver }\end{array}$ & é & $\begin{array}{c}\text { muito } \\
\text { diferente } \\
\text { do nosso }\end{array}$ & por isso & (nós) & $\begin{array}{c}\text { estranha- } \\
\text { mos }\end{array}$ & $\begin{array}{c}\text { o seu } \\
\text { modo } \\
\text { de viver }\end{array}$ \\
\hline $\begin{array}{c}\text { Partici- } \\
\text { pante: } \\
\text { Portador }\end{array}$ & $\begin{array}{c}\text { Pelacional } \\
\text { atributivo } \\
\text { intensivo }\end{array}$ & $\begin{array}{c}\text { Partici- } \\
\text { pante: } \\
\text { Atributo }\end{array}$ & Conector & $\begin{array}{c}\text { Partici- } \\
\text { pante: } \\
\text { Expe- } \\
\text { riencia- } \\
\text { dor }\end{array}$ & $\begin{array}{c}\text { Mental de } \\
\text { percepção }\end{array}$ & $\begin{array}{c}\text { Partici- } \\
\text { pante: } \\
\text { Fenô- } \\
\text { meno }\end{array}$ \\
\hline $\begin{array}{c}\text { Muitas } \\
\text { pessoas }\end{array}$ & \multicolumn{2}{|c|}{ são } & preconceituosas & $\begin{array}{c}\text { em relação a } \\
\text { outra raça, }\end{array}$ & outro modo de \\
viver
\end{tabular}

(6)

\begin{tabular}{|c|c|c|c|}
\hline Eles & são & muitos fechados & em sua cultura \\
\hline $\begin{array}{c}\text { Participante: } \\
\text { Portador }\end{array}$ & $\begin{array}{c}\text { Processo: Relacional } \\
\text { atributivo intensivo }\end{array}$ & Participante: Atributo & Circunstância \\
\hline
\end{tabular}

(7)

\begin{tabular}{|c|c|c|c|c|}
\hline Bom & para as pessoas & ser índio & é & $\begin{array}{l}\text { motivo de } \\
\text { muito precon- } \\
\text { ceito }\end{array}$ \\
\hline $\begin{array}{l}\text { Adjunto } \\
\text { (modal) }\end{array}$ & Circunstância & $\begin{array}{l}\text { Participante: } \\
\text { Identificado } \\
\text { Característica }\end{array}$ & $\begin{array}{c}\text { Processo: } \\
\text { Relacional } \\
\text { identificativo } \\
\text { circunstâncial }\end{array}$ & $\begin{array}{c}\text { Participante: } \\
\text { Identificador } \\
\text { Valor }\end{array}$ \\
\hline
\end{tabular}

(8)

\begin{tabular}{|l|l|l|l|}
\hline Pra mim & ser índio & é & ser humano \\
\hline Adjunto (modal) & $\begin{array}{l}\text { Participante: } \\
\text { Portador }\end{array}$ & $\begin{array}{l}\text { Processo: Relacional atributivo } \\
\text { intensivo }\end{array}$ & $\begin{array}{l}\text { Participante: } \\
\text { Atributo }\end{array}$ \\
\hline
\end{tabular}


(9)

\begin{tabular}{|c|c|c|c|c|c|}
\hline Ser índio & para as pessoas & ser índio & não & é & legal \\
\hline Partici- & Circunstância & Participante: & Polaridade & Processo: & Participan- \\
pante: & & Portador & negativa & Relacional & te: \\
Portador & & & & $\begin{array}{c}\text { atributivo } \\
\text { intensivo }\end{array}$ & Atributo \\
\hline
\end{tabular}

(10)

\begin{tabular}{|c|c|c|c|}
\hline As pessoas & se & acham & melhores do que eles \\
\hline $\begin{array}{c}\text { Participante: } \\
\text { Experenciador }\end{array}$ & $\begin{array}{c}\text { Adjunto } \\
\text { (modal) }\end{array}$ & $\begin{array}{c}\text { Processo: Mental } \\
\text { de percepção }\end{array}$ & Participante: Fenômeno \\
\hline
\end{tabular}

(11)

\begin{tabular}{|c|c|c|c|}
\hline Na minha opinião & ser índio & é & ser maravilhoso \\
\hline Adjunto (modal) & Participante: & Processo: & Participante: \\
& Identificado & Relacional identifica- & Identificador \\
& Característica & tivo intensivo & Valor \\
\hline
\end{tabular}

\begin{tabular}{|c|c|c|c|c|}
\hline pois & eles & são & importante & $\begin{array}{c}\text { para a cultura } \\
\text { do país }\end{array}$ \\
\hline Conector & $\begin{array}{c}\text { Participante: } \\
\text { portador }\end{array}$ & $\begin{array}{c}\text { Processo: Relacional } \\
\text { atributivo intensivo }\end{array}$ & $\begin{array}{c}\text { Participante: } \\
\text { Atributo }\end{array}$ & Circunstância \\
\hline
\end{tabular}

(12)

\begin{tabular}{|c|c|c|c|}
\hline Índio & é & um ser normal & $\begin{array}{c}\text { como qualquer } \\
\text { outro ser humano }\end{array}$ \\
\hline $\begin{array}{c}\text { Participante: } \\
\text { Identificado } \\
\text { Característica }\end{array}$ & $\begin{array}{c}\text { Processo: Relacional } \\
\text { identificativo intensivo }\end{array}$ & $\begin{array}{c}\text { Participante: } \\
\text { Identificador Valor }\end{array}$ & Circunstância \\
\hline
\end{tabular}

(13)

\begin{tabular}{|c|c|c|c|c|}
\hline Os índio & pra mim & não & são & $\begin{array}{c}\text { nem melhor } \\
\text { nem pior }\end{array}$ \\
\hline $\begin{array}{c}\text { Participante: } \\
\text { Portador }\end{array}$ & Circunstância & $\begin{array}{c}\text { Polaridade } \\
\text { negativa }\end{array}$ & $\begin{array}{c}\text { Processo: Relacional } \\
\text { atributivo intensivo }\end{array}$ & $\begin{array}{c}\text { Participante: } \\
\text { Atributo }\end{array}$ \\
\hline
\end{tabular}




\begin{tabular}{|c|c|c|}
\hline Ser índio & é & ser uma pessoa que gosta da natureza \\
\hline $\begin{array}{c}\text { Participante: } \\
\text { Portador }\end{array}$ & $\begin{array}{c}\text { Processo: Relacional } \\
\text { atributivo intensivo }\end{array}$ & Participante: Atributo \\
\hline
\end{tabular}

(15)

\begin{tabular}{|c|c|c|c|c|}
\hline Os índios & também & tem & $\begin{array}{c}\text { um papel } \\
\text { importante }\end{array}$ & $\begin{array}{c}\text { para o } \\
\text { Brasil }\end{array}$ \\
\hline $\begin{array}{c}\text { Participante: } \\
\text { Possuidor }\end{array}$ & $\begin{array}{c}\text { Circuns- } \\
\text { tância }\end{array}$ & $\begin{array}{c}\text { Processo: Relacional } \\
\text { atributivo possessivo }\end{array}$ & $\begin{array}{c}\text { Participante: } \\
\text { Possuído }\end{array}$ & $\begin{array}{c}\text { Circuns- } \\
\text { tância }\end{array}$ \\
\hline
\end{tabular}

(16)

\begin{tabular}{|c|c|c|c|}
\hline Ser índio & é ter & $\begin{array}{c}\text { uma cultura dife- } \\
\text { rente }\end{array}$ & $\begin{array}{c}\text { dos homens } \\
\text { brancos }\end{array}$ \\
\hline $\begin{array}{c}\text { Participante: } \\
\text { Possuidor }\end{array}$ & $\begin{array}{c}\text { Processo: Relacional } \\
\text { atributivo possessivo }\end{array}$ & $\begin{array}{c}\text { Participante: } \\
\text { Possuído }\end{array}$ & Circunstância \\
\hline
\end{tabular}

(17)

\begin{tabular}{|c|c|c|c|}
\hline os índios & devem ser & respeitados & como ser humano \\
\hline Participante: & Processo: Relacio- & Participante: & Circunstância \\
Identificado & nal identificativo & Identificador valor & \\
característica & intensivo & & \\
\hline
\end{tabular}

(18)

\begin{tabular}{|l|l|l|l|}
\hline As pessoas & deviam tratar & os índios & com mais educação \\
\hline Participante: ator & Processo: material & Participante: meta & Circunstância \\
\hline
\end{tabular}

(19)

\begin{tabular}{|c|c|c|c|c|c|}
\hline eu & acho & $\begin{array}{c}\text { que a } \\
\text { criação } \\
\text { do índio }\end{array}$ & $\begin{array}{l}\text { (criação do } \\
\text { índio) }\end{array}$ & deveria ser & igual a nós \\
\hline $\begin{array}{l}\text { Partici- } \\
\text { pante: } \\
\text { experien- } \\
\text { ciador }\end{array}$ & $\begin{array}{c}\text { Processo: } \\
\text { mental }\end{array}$ & $\begin{array}{c}\text { Partici- } \\
\text { pante: } \\
\text { Fenômeno }\end{array}$ & $\begin{array}{l}\text { Participante: } \\
\text { Identificado } \\
\text { característica }\end{array}$ & $\begin{array}{c}\text { Processo: } \\
\text { Relacional } \\
\text { identificativo } \\
\text { intensivo }\end{array}$ & $\begin{array}{c}\text { Participante: } \\
\text { Identificador } \\
\text { Valor }\end{array}$ \\
\hline
\end{tabular}

(20) 


\begin{tabular}{|c|c|c|}
\hline Ser índio & é ter & $\begin{array}{c}\text { toda liberdade federal, estadual e } \\
\text { municipal }\end{array}$ \\
\hline $\begin{array}{c}\text { Participante: } \\
\text { Possuidor }\end{array}$ & $\begin{array}{c}\text { Processo: Relacional } \\
\text { atributivo possessivo }\end{array}$ & Participante: Possuído \\
\hline
\end{tabular}

(21)

\begin{tabular}{|c|c|c|c|c|c|}
\hline os indios & tem & $\begin{array}{l}\text { toda li- } \\
\text { berdade }\end{array}$ & $\begin{array}{l}\text { que nós } \\
\text { brancos }\end{array}$ & não & temos \\
\hline $\begin{array}{c}\text { Participante: } \\
\text { Possuidor }\end{array}$ & $\begin{array}{l}\text { Processo: } \\
\text { Relacional } \\
\text { atributivo } \\
\text { possessivo }\end{array}$ & $\begin{array}{l}\text { Partici- } \\
\text { pante: } \\
\text { Possuído }\end{array}$ & $\begin{array}{c}\text { Partici- } \\
\text { pante: } \\
\text { Possuidor }\end{array}$ & $\begin{array}{c}\text { Polaridade } \\
\text { negativa }\end{array}$ & $\begin{array}{l}\text { Relacional } \\
\text { atributivo } \\
\text { possessivo }\end{array}$ \\
\hline
\end{tabular}

\begin{tabular}{|c|c|c|c|}
\hline Ser índio & é & ser liberal & com tudo e com todos \\
\hline $\begin{array}{c}\text { Participante: } \\
\text { Portador }\end{array}$ & $\begin{array}{c}\text { Processo:Relacional } \\
\text { atributivo intensivo }\end{array}$ & $\begin{array}{c}\text { Participante: } \\
\text { Atributo }\end{array}$ & Circunstância \\
\hline
\end{tabular}

(22)

\begin{tabular}{|l|l|l|}
\hline Eles & são & quais igual a nós brancos \\
\hline $\begin{array}{l}\text { Participante: } \\
\begin{array}{l}\text { Identificado } \\
\text { característica }\end{array}\end{array}$ & $\begin{array}{l}\text { Processo: Relacional identificati- } \\
\text { vo intensivo }\end{array}$ & Participante: Identificador valor \\
\hline
\end{tabular}

Embora se trate de uma análise qualitativa, podemos ilustrar as ocorrências nos textos analisados quantitativamente. Nos 120 enunciados analisados, $79 \%$ dos processos encontrados são processos relacionais, conforme mostra o gráfico abaixo: 


\section{Gráfico 1 - Análise dos processos nos textos dos alunos não índios}

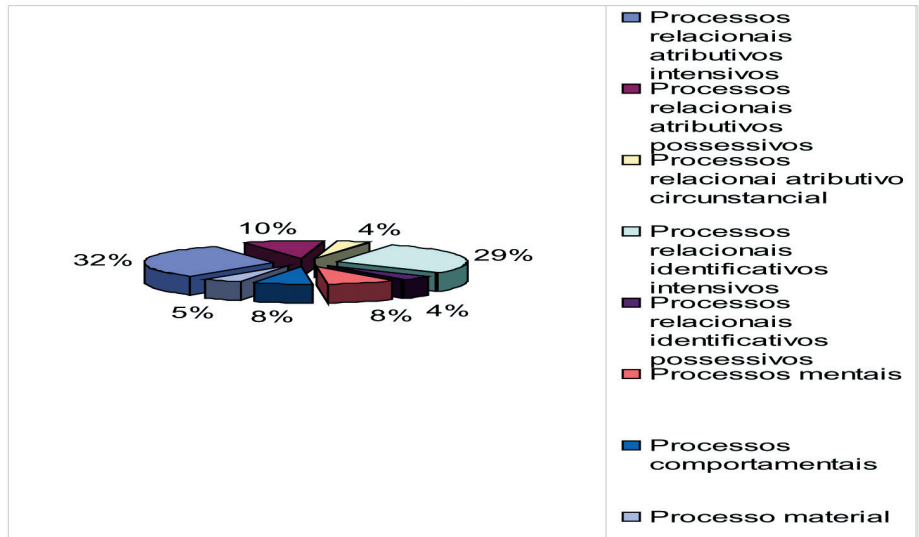

A análise desses processos ajuda a compreender que recursos lingüísticos são usados para construir a identidade do índio, como os índios estão sendo avaliados. De acordo com Halliday (1985: 112), esses processos destacadamente relacionais apresentam estados de identidade e de posse. Portanto, os atributos e valores concedidos a um grupo revelam o tipo de identidade que está sendo construída. Os atributos e valores mais freqüentes nos textos foram os seguintes:

Quadro 1 - Atributos e valores nos textos de alunos(as) não índios(as)

\begin{tabular}{|l|c|}
\hline \multicolumn{1}{|c|}{ Atributos } & \multicolumn{1}{c|}{ Valores } \\
\hline cultura & discriminados \\
diferente & normais \\
igual a um cristão & igual a nós \\
como nós & liberal \\
costumes diferentes & igual a nós brancos \\
fechados & diferente \\
humano & \\
normal & \\
\hline
\end{tabular}


Nas afirmações avaliativas, que representam juízo de valor, notamos que ao portador (índio) são destinados atributos negativos, como por exemplo, ser muito diferente (4)/muito diferente do nosso (5)/muitos fechados em sua cultura (6). Isso revela que a diferença é marcada negativamente e, para superá-la, esses portadores (índios) necessitam se assemelhar a não índios. Os atributos igual a nós (3)/ como nós (19)/quais igual a nós (22) denunciam a construção de uma identidade legitimadora, pois os índios só são aceitos à medida que possuam atributos semelhantes aos de não índios, à medida que se comportem como não índios, como deixam claro os valores com os quais são identificados: igual a um cristão (3)/motivo de preconceito (7)/igual a nós (19). Como afirma Thompson (2004: 87), "os processos intensivos identificativos são utilizados para identificar uma entidade em termos de outra", em que uma entidade (índio) carrega atributos de outra (não índio), revelando, assim, uma avaliação negativa.

Desse modo, Hall (2008) argumenta que um processo necessário para a construção dessas identidades é a identificação ${ }^{14}$. $\mathrm{Na}$ linguagem do senso comum, a identificação é construída a partir do reconhecimento de alguma origem comum, ou de características que são partilhadas com outros grupos ou pessoas, ou ainda a partir de um mesmo ideal. Entretanto, Hall destaca que a identificação é uma construção, um processo nunca completado, um continum. Pois, ela não é, nunca, completamente determinada - no sentido de que se pode, sempre, 'ganhá-la ou 'perdê-la'; no sentido de que ela pode ser, sempre, sustentada ou abandonada (Hall, 2008: 106). Nesse sentido, a tentativa de identificar os xerentes como "igual ou quase igual aos não índios" é processo discursivo na luta pela classificação, pois os processos de identificação sempre ocorrem em um contexto marcado por relações de poder.

Como observa Castells (1999), as identidades legitimadoras são introduzidas pelas instituições da sociedade no intuito de fortalecer a dominação em relação aos atores sociais. Assim, os atributos que as

14. Segundo Hall, num processo, a identificação opera por meio da différance, ela envolve um trabalho discursivo, o fechamento e a marcação de fronteiras simbólicas, a produção de 'efeito de fronteiras'. (Hall, 2008:106). 
instituições constroem para descrever e explicar a natureza das suas funções e a conseqüente legitimidade de suas ações são os mesmos que estruturam e descrevem o acesso dos atores sociais aos meios e as formas de participação. Desse modo, os atributos destinados aos índios revelam que os alunos(as) não índios(as) representam negativamente essa diferença e que essa constante representação não é uma construção individual, pois "os sentidos das palavras entram em disputa dentro de lutas mais amplas, sugerindo que as estruturações particulares das relações entre os sentidos de uma palavra são formas de hegemonia ${ }^{15 ”}$ (Fairclough, 2001).

Essa construção do sentido de "ser índio" faz parte de uma luta hegemônica que está relacionada à articulação, desarticulação e rearticulação de hegemonias, em uma concepção dialética da relação entre eventos discursivos (Fairclough, 2003). Ao tentar classificar o xerente como "normal”, semelhante ao não índio, percebemos nas práticas discursivas de não índios um esforço para moldar e naturalizar o seguinte pressuposto ideológico: o índio só é considerado um ser social, um sujeito, quando se assemelha, vive e se comporta como o não índio. Trata-se de uma prática discursiva dominante no corpus analisado que consiste em permitir a perpetuação da ideologia por meio da reificação, retratação de uma situação transitória como permanente, natural e atemporal. Assim, percebemos que a luta hegemônica sobre os modos de identificação nas práticas discursivas analisadas é a luta pela fixação/estabilização da construção identitária do xerente pela negação da diferença.

A esse respeito, Fairclough (2003) considera que a prática e a luta hegemônica assumem a forma da prática discursiva, uma vez que o conceito de hegemonia implica o desenvolvimento de práticas que naturalizam relações ideológicas específicas. Essas são, na sua maioria, práticas discursivas, e também, porque o próprio discurso constitui-se em uma esfera de hegemonia, visto que a hegemonia de um grupo depende de sua capacidade de moldar práticas discursivas

15. Fairclough (1997) define hegemonia como uma forma de liderança e de dominação econômica, política, cultural e ideológica exercida pelo poder de um grupo sobre os demais. 
tão eficientes quanto forem capazes de exercer a manutenção da hegemonia existente. Assim, é precisamente porque as identidades são construídas dentro e não fora do discurso que nós precisamos compreendê-las como produzidas em locais históricos e institucionais específicos, no interior de formações e práticas discursivas específicas, por estratégias e iniciativas específicas (Hall, 2003:109).

A avaliação, por meio de presunções valorativas (informações explícitas e implícitas), aparece, por exemplo, nos atributos toda liberdade federal, estadual, municipal (20)/toda liberdade (21)/ ser liberal (21), pois afirmar que ser índio é ter toda liberdade deixa implícito que os índios, diferentemente dos não índios, não necessitam cumprir determinadas "regras sociais", são pessoas sem ordem com "um jeito de viver muito diferente", o que é motivo de muito preconceito como evidenciam os exemplos (7) e (9). Esses atributos revelam que a "cultura diferente" seria algo como o verso inconsciente cujo anverso é a vida civilizada, as crenças e predileções tomadas como certas que têm de estar vagamente presentes. Neste sentido, a idéia de cultura está relacionada a um modo de vida característico e está estritamente ligada a um pendor romântico anti-colonialista por sociedades "exóticas" subjugadas (Eagleton, 2005: 43-44). O índio, apesar de morar na mesma cidade e estudar na mesma escola, é representado como um sujeito "exótico", "diferente" que deve se comportar "igual a um cristão".

Outro caso de presunção valorativa ocorre no exemplo (3) em que o índio aparece como portador do atributo "tudo de bom" e recebedor da meta "de tudo", enquanto o governo aparece como ator, aquele que supre os índios de necessário para que "eles procigam [prossigam] a nação cada vez mais". Neste exemplo, o processo material "dá" [dar] carrega uma conotação negativa, pois o índio é representado como um sujeito dependente (o que recebe) dos não índios, representados pela figura do governo (os que dão).

Ocorre, também, nos enunciados analisados, avaliação por meio de afirmações com processos mentais. Esses lidam com a apreciação humana do mundo e, por meio de sua análise, é possível detectar que crenças, valores e desejos estão representados em um 
dado texto. Nos enunciados analisados, em que foram encontrados processos mentais, notamos que os fenômenos experienciados pelos índios (experienciador) revelam marcas de não-aceitação, exclusão, preconceito: o seu modo de viver (5)/diferente (6)/melhores que eles (10). Os costumes, as crenças, o modo de viver dos índios são justificativa da não aceitação, como podemos ver no exemplo (9), "ser índio não é legal, e no exemplo (19), "a criação dos índios deveria ser igual a nós".

Nesse sentido, Fairclough (2001:104) argumenta que as escolhas que as pessoas fazem sobre o modelo e as estruturas de suas orações resultam em escolhas sobre o significado (e a construção) de identidades sociais, relações sociais e crença. Thompson (2004) argumenta também que, por meio das escolhas dos processos, é possível identificar que os processos indicam a escolha "consciente" por parte de falantes de uma forma de representação de mundo em detrimento de outras. Isso é muito importante para compreendermos como os(as) alunos(as) índios(as) estão sendo avaliados pelos(as) alunos(as) não índios(as) e, consequentemente, como está sendo construída a identidade xerente naquele ambiente escolar, visto que, de acordo Halliday (2001), o tipo de escolha feita por uma pessoa é opcional e relativa a fatores psicológicos e sociais e, que por conseguinte, reflete características da constituição da identidade do sujeito.

Nesse contexto, podemos perceber claramente como a identidade xerente está sendo construída por meio da marcação da diferença e, essa marcação, ocorre tanto por meio de sistemas simbólicos de representação, quanto por meio de formas de exclusão social. Assim, a forma como a diferença é marcada na construção discursiva da identidade indígena revela as formas de exclusão de um grupo. A identidade xerente está fundada sobre a construção de uma fronteira de exclusão e depende da construção de um "Outro" e de uma oposição rígida entre quem está "dentro" e quem está "fora" (Hall, 2009: 33).

Desse modo, para os não índios, seu modo de vida é simplesmente "normal"; são os Outros (os índios) que são diferentes, idiossincráticos, culturalmente peculiares: só pensa diferente (4)/, 
modo de viver muito diferente (6), muitos fechados (6), cultura diferente (16). Assim, a "cultura" pode descrever uma ordem social "primitiva", como também pode fornecer a alguém um modo de idealizar a sua própria (Eagleton, 2005: 25). Portanto, os alunos(as) índios(as) são denominados no discurso dos alunos(as) não índios(as) como o "Outro", os "fechados", os "diferentes".

Logo, todas as práticas de significação, que produzem significados envolvem relações de poder, incluindo o poder para definir quem é incluído e quem é excluído, pois a cultura molda a identidade ao dar sentido à experiência e ao tornar possível optar, entre várias identidades possíveis, por um modo especifico de subjetividade (Woodward, 2008: 18-19). Dessa forma, a (des)construção desses significados, tendo em vista a produção da conscientização e da emancipação, estão na pauta da ADC, pois entre os múltiplos espaços e as muitas instâncias onde se pode observar a instituição das distinções e das desigualdades, a linguagem é, seguramente, o campo mais eficaz e persistente. Ela não apenas expressa relações, poderes, lugares, ela os institui; ela não apenas veicula, mas produz e pretende fixar diferenças (Louro, 2001: 65).

A identificação e compreensão dos elementos avaliativos que contribuem para a constituição das identidades xerentes no espaço escolar multicultural são, então, de suma importância para que determinadas representações sejam problematizadas e para que práticas sociais e discursivas sejam transformadas, visando o reconhecimento da diferença e do direito à diferença, abrindo caminhos para emancipação social. Dessa maneira, reconhecer a diferença é reconhecer que existem indivíduos e grupos que são diferentes entre si, mas que possuem direitos correlatos, e que a convivência em uma sociedade democrática depende da aceitação da ideia de compormos uma totalidade social heterogênea na qual não poderá ocorrer a exclusão de nenhum elemento da totalidade e os conflitos de interesse e de valores deverão ser negociados pacificamente (Candau, 2006). 


\section{Considerações finais}

A análise do corpus permite-nos observar que os atributos e valores destinados aos estudantes índios agrupam-se em conjuntos semânticos de termos que revelam valores negativos condenáveis para a cultura ocidental, revelando que os(as) alunos(as) não índios(as) representam negativamente a diferença. Essa representação não é uma construção individual, mas faz parte de uma luta hegemônica relacionada à articulação, desarticulação e rearticulação de hegemonias, em uma concepção dialética da relação entre eventos discursivos.

Os textos analisados denunciam a presença de uma voz que identifica o índio como um ser que não se enquadra na "ordem social” e, portanto, é estranho. Para ser aceito, é necessário que se assemelhe aos não índios. Dessa forma, podemos classificar o discurso em análise como um discurso hegemônico, que, apesar de possuir um equilíbrio instável, está sempre em luta sobre os pontos de instabilidade para construir e manter relações de dominação e de subordinação.

Os atributos e valores destinados aos índios revelam, em grande parte, a construção de uma identidade legitimadora que ofusca, nega, apaga as diferenças, seja por meio do processo de marcação da diferença (cultura diferente) ou pela assimilação social (igual a um cristão). Assim, se as identidades sociais são constructos discursivos, é possível a desconstrução dessa representação negativa do "ser índio", já que o significado não possui origem nem destino final, não pode ser fixado, está sempre em processo e "posicionado" ao longo de um "espectro", de um "simulacro"; seu valor político não pode ser essencializado, apenas determinado em termos relacionais.

Dessa forma, refletir no espaço escolar multicultural sobre identidade, diferença, exclusão, aceitação é fundamental para desvelar discursos pretensamente "universais" que silenciam e "engessam" identidades diversificadas como, também, para desconstruir estereótipos que mascaram a "não aceitação da 
diferença" e, por conseguinte, para conquistar a cidadania multicultural espaço de integração plena, de potenciação mútua do reconhecimento, de ruptura da homogeneidade e de proliferação da heterogeneidade.

Portanto, a ADC e a LSF em muito podem contribuir para a desconstrução dessas representações excludentes, desvelando discursos que servem de base para manutenção de relações assimétricas de poder e para o mascaramento de estereótipos que geram desigualdade social, pois revelam as atitudes, crenças, valores, certezas e os domínios de conhecimento das pessoas.

Recebido em: 02/09/2011

Aprovado em: 15/10/2011

lecaldeira3@hotmail.com

\section{Referências bibliográficas}

BAUER, M. W.; GASKELL, G. Pesquisa qualitativa com texto, imagem e som: um manual prático. São Paulo: Vozes, 2003.

BAUMAN, Z. Identidade - Entrevista a Benedetto Vecchi. Trad. Carlos Alberto Medeiros. Rio de Janeiro: Jorge Zahar Editor, 2005.

BHABHA, H. K. O local da cultura. Trad. Myriam Ávila, Eliana Lourenço de Lima Reis, Gláucia Renate Gonçalves. Belo Horizonte: UFMG, 1998.

CANDAU, V. M. (org). Educação Intercultural e Cotidiano escolar. $7^{\circ} \mathrm{ed}$. Rio de Janeiro: Letras, 2006.

CASTELLS, M. O poder da identidade. Trad. K. B. Gerhardt. São Paulo: Paz e Terra, 1999.

CHOULIARAKI, L. Political discourse in the news: democratizing responsability or aestheticizing politics? Discourse \& Society. Londres: Sage Publications, 2000.

CHOULIARAKI, L. \& N. FAIRCLOUGH. Discourse in late modernity. Rethinking critical discourse analysis. Edinburgh: Edinburgh University Press, 1999. 
EAgleton, T. A idéia de cultura. Trad. Sandra Castello Branco. São Paulo: UNESP, 2005.

FAIRCLOUGH, N. Discurso, mudança e hegemonia. In: PEDRO, Emília. (org.). Análise Crítica do Discurso: uma perspectiva sociopolítica e funcional. Lisboa: Editorial Caminho, 1997.

FAIRCLOUGH, N. Discurso e mudança social. Trad. I. Magalhães. Brasilía: Universidade de Brasília, 2001.

FAIRCLOUGH, N. Analysing discourse. Textual analysis for social research. London: Routledge, 2003.

FLICK, U. Uma introdução à pesquisa qualitativa. Porto Alegre: Bookman, 2004. GIDDENS, A. As conseqüencias da modernidade. Trad. Raul Fiker. São Paulo: Unesp, 1991.

. Modernidade e identidade. Trad. Plínio Dentzien. Rio de Janeiro: Jorge Zahar, 2002.

GOUVEIA, C. Texto e Gramática: Uma Introdução à Linguística SistémicoFuncional. Matraga, Rio de Janeiro, v.16, n.24, jan./jun. 2009.

HALL, S. The work of representation. Trad. Ricardo Uebel. In: Hall, Stuart. Representation: cultural representation and signifying practices. London/ Thousand Oaks/New Delhi: Sage/The Open University, 1997.

HALL, S. A Identidade Cultural na Pós-Modernidade. Trad. Tomaz da Silva e Guacira Louro. 5 ed. Rio de Janeiro: DP\&A, 2000.

HALL, S. A relevância de Gramsci para o estudo de raça e etnicidade. In: Da diáspora: Identidades e mediações culturais. Belo Horizonte: UFMG, 2003, p.294 -333.

HALL, S. Quem precisa de identidade? In: SILVA, Tomas Tadeu da (Org.). Identidade e diferença: a perspectiva dos Estudos Culturais. Petrópolis, RJ: Vozes, 2008, p. 103-133.

HALL, S. A questão da identidade cultural. Textos didáticos. São Paulo: IFHC/Unicamp, 2009.

HALLIDAY, M.A.K. An introduction to functional grammar, $2{ }^{a}$ ed. Londres, Arnold, 1994.

HALLIDAY, M.A.K. El lenguaje como semiotica social - la interpretacion social Del languaje y del significado, México: Fondo de Cultura Economica, 2001. 
HALLIDAY, M.A.K. An Introduction to Functional Grammar. 3rd ed. Revised by C. M. I. M. Matthiessen. London: Arnold, 2004.

LOURO, Guacira Lopes. Gênero, sexualidade e educação. 4 ed. Petrópolis, RJ, Vozes, 2001.

RAJAGOPALAN, K. Por uma lingüística crítica: linguagem, identidade e a questão ética. São Paulo: Parábola, 2003.

RAMALHO, V. Análise crítica da publicidade: um estudo sobre anúncios de medicamento. Cadernos de Linguagem e Sociedade, v. 10 (2), 2009, p. 152 182.

RAMALHO, V.; RESENDE, V. M. Análise de discurso (para a) crítica: o texto como material de pesquisa. Campinas, SP: Pontes Editores, 2011.

RESENDE, V. M. Análise de Discurso Crítica e Realismo Crítico: Implicações Interdisciplinares. Campinas, São Paulo: Pontes Editores, 2009.

RESENDE, V. M.; RAMALHO, V. Análise de Discurso Crítica. São Paulo: Contexto, 2006.

SILVA, T. T. Identidade e diferença: a perspectiva dos estudos culturais. Petrópolis: Vozes, 2008.

THOMPSON, G. Introducing functional grammar. $2^{\mathrm{a}}$ ed. London: Edward Arnold, 2004.

WODAK, R. What CDA is about: a summary of its history, important concepts and its development. In: WODAK, R.; MEYER, M. (eds.). Methods of critical discourse analysis. Londres; Thousand Oaks; Nova Delhi: Sage, 2001. p. $1-13$.

WOODWARD, K. A produção social da identidade e da diferença. In: SILVA, Tomaz Tadeu da (org.). Identidade e diferença: a perspectiva dos estudos culturais. 8.ed. Petrópolis, RJ: Vozes, 2008. 